\title{
ERRATUM
}

Harufumi Nishida • Kathleen B. Pigg • Kensuke Kudo

John F. Rigby

\section{Zooidogamy in the Late Permian genus Glossopteris}

Published online: September 30, 2004

\section{J Plant Res (2004) 117:323-328}

The received/accepted dates of the article were inadvertently omitted. This article was received on December 17, 2003, and accepted on May 27, 2004.

The online version of the original article can be found at http://dx.doi.org/10.1007/s10265-004-0164-4

H. Nishida $(\bowtie)$

Faculty of Science and Engineering, Chuo University, 1-13-27 Kasuga,

Bunkyo-Ku, Tokyo 112-8551, Japan

Tel. +81-3-38171886; Fax +81-3-38171880

e-mail: helecho@kc.chuo-u.ac.jp

K.B. Pigg

Arizona State University, Tempe, AZ, USA

K. Kudo

Sankyo Labo Service Corporation, Tokyo, Japan

J.F. Rigby

Queensland University of Technology, Brisbane, Australia 